\title{
Visualization of hidden soft-tissue recurrence of giant cell tumor of bone enabled by preoperative denosumab treatment: a case description
}

\author{
Takeo Suzuki $^{1}$, Yoichi Kaneuchi ${ }^{2} \wedge$, Michiyuki Hakozaki $^{2,3} \wedge$, Hitoshi Yamada ${ }^{2,4}$, Shoki Yamada $^{5}$, \\ Shinichi Konno ${ }^{2} \wedge$ \\ ${ }^{1}$ Fukushima Medical University Hospital, Fukushima, Japan; ${ }^{2}$ Department of Orthopaedic Surgery, Fukushima Medical University School of \\ Medicine, Fukushima, Japan; ${ }^{3}$ Higashi-Shirakawa Orthopaedic Academy, Fukushima Medical University School of Medicine, Fukushima, Japan; \\ ${ }^{4}$ Department of Musculoskeletal Oncology and Metabolic Bone Disease Research, Fukushima Medical University School of Medicine, Fukushima, \\ Japan; ${ }^{5}$ Department of Pathology and Diagnostic Pathology, Fukushima Medical University School of Medicine, Fukushima, Japan
}

Correspondence to: Dr. Michiyuki Hakozaki. Department of Orthopaedic Surgery, Fukushima Medical University School of Medicine, 1 Hikarigaoka, Fukushima-shi, Fukushima 960-1295, Japan. Email: paco@fmu.ac.jp.

Submitted Oct 15, 2020. Accepted for publication Feb 17, 2021.

doi: 10.21037/qims-20-1157

View this article at: http://dx.doi.org/10.21037/qims-20-1157

\section{Case presentation}

An 18-year-old Japanese female presented to prior hospital with a 3-month history of pain in the right proximal lower leg and gradually progressive muscle weakness of the ankle dorsiflexion. A radiological examination suggested a bone tumor of the fibular head (Figure 1A,B), and the patient was then referred to our hospital. Magnetic resonance imaging (MRI) showed an expansile and osteolytic lesion in the proximal fibula with extraosseous extension (Figure 1C,D). After a needle biopsy, the lesion was diagnosed as a giant cell tumor of bone (GCTB), Campanacci grade III (1), and we performed a tumor resection.

The intraoperative gross findings revealed an extraosseous tumor involving the common peroneal nerve, and we dug out and preserved the nerve from the tumor (Figure 1E,F). The histopathological examination showed typical numerous osteoclast-like multinuclear giant cells and mononuclear neoplastic stromal cells (Figure 1G). Mononuclear neoplastic stromal cells showed immunopositivity for H3.3 G34W, characteristics of GCTB, but multinuclear giant cells were negative (Figure $1 H)$. The patient was finally diagnosed as a GCTB. Although common peroneal nerve palsy temporarily occurred after the operation, it spontaneously recovered within approx. 6 months.

Nineteen months after the surgery, plain radiographs of the right lower leg showed a tiny ossification in the soft tissue of the posterior to fibula stump (Figure 2A,B), MRI demonstrated a mass in the soft tissue anterior to the fibula stump (Figure 2C,D), and the lesions observed were considered a latent recurrence. Considering the intraoperative findings, we suspected that there was a possibility that spread recurrent tumors that were not visible to the naked eye were present around the preserved common peroneal nerve. Therefore, before the resection of the recurrent lesion, the patient underwent nine courses of preoperative denosumab treatment, injecting $120 \mathrm{mg}$ of subcutaneous denosumab every four weeks with loading doses on days 8 and 15, for the purposes of visualizing the hidden recurrent tumors by mineralization and shrinking the recurrent tumor.

Six months later, the recurrent lesion had shrunk in size and eggshell-like ossification appeared, and another ossification appeared in the surrounding soft tissue inferior to the fibula stump on plain radiographs (Figure $2 E, F$ ) and MRI (Figure 2G,H). We performed a marginal resection of

^ ORCID: Yoichi Kaneuchi, 0000-0002-6682-8236; Michiyuki Hakozaki, 0000-0003-1641-0795; Shinichi Konno, 0000-0002-2861-2194. 

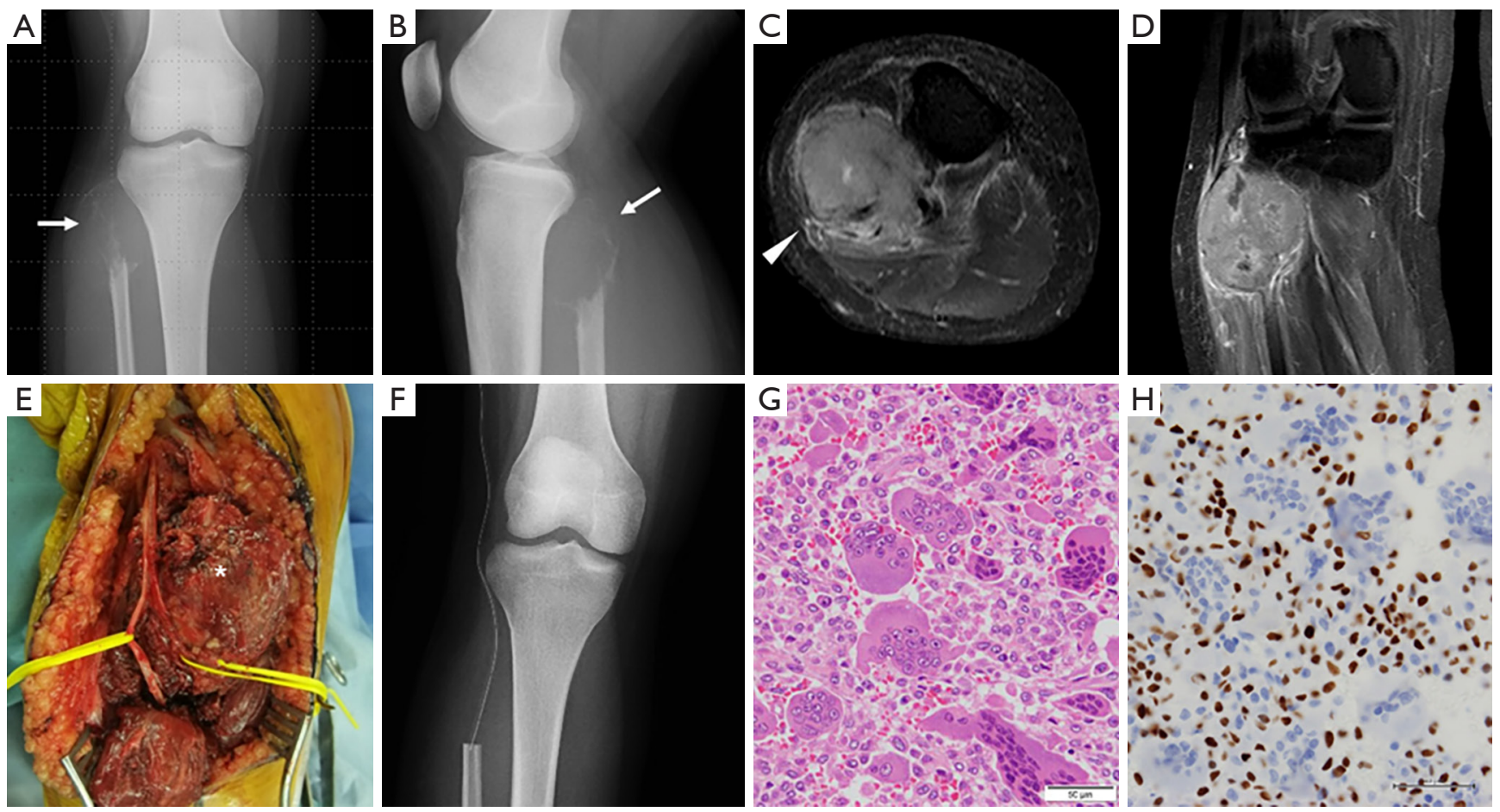

Figure 1 Imaging of primary giant cell tumor of the fibular head. Plain anteroposterior (A) and lateral (B) radiographs showing an expansive osteolytic lesion localized in the right proximal fibula (arrow). Axial MRI showing a proximal fibular tumor, displaying high intensity on short-tau inversion recovery $(\mathrm{C})$. Coronal gadolinium-enhanced T1-weighted fat-suppressed imaging showing a homogeneously enhanced extensive tumor (D). Intraoperative findings showing the bone tumor extending extraosseously and involving the common peroneal nerve (E). Postoperative plain radiograph showing the bone defect caused by the fibular head resection (F). Histopathological examination of a resected specimen showing numerous osteoclast-like multinuclear giant cells and mononuclear neoplastic stromal cells. Hematoxylin-eosin (HE) staining, high-power field (×400) (G). Immunohistochemistry for H3.3 G34W showing positivity in mononuclear neoplastic stromal cells and negativity in osteoclast-like multinuclear giant cells $(\times 400)(\mathrm{H})$.

these two lesions (Figure $3 A, B, C$ ). The histopathological examination showed eggshell-like ossification on the periphery of the tumor and mononuclear cells and foamy cells on the central area, but no giant cells were observed (Figure 3D,E). Since mononuclear cells were positive for H3.3 G34W (Figure 3F), we judged that the cells are neoplastic. There was no tumor cell outside the peripheral ossification. Four years after the second surgery, there is no sign of local recurrence or distant metastasis.

\section{Discussion}

GCTB is an intermediate (locally aggressive) primary bone tumor with a high recurrence rate $(2,3)$. In particular, in the Campanacci grade III (1) cases that extend into circumferential soft tissue with cortical destruction, postoperative local recurrence in the surrounding soft tissue as well as in the bone is an issue of great concern.

GCTB is histologically characterized by the diffuse growth of RANKL [receptor activator of nuclear factor$\kappa \mathrm{B}$ (RANK) ligand]-positive mononuclear neoplastic stromal cells and RANK-positive osteoclast-like giant cells. RANKL is a key mediator, which orchestrates the recruitment of monocyte cells to their milieu, incites the production of the multinuclear giant cells and activates osteoclasts. The RANK-RANKL interaction in GCTB is thought to participate in the production of multinuclear giant cells which express mediators degrading the organic and hydroxyapatite component of bone, leading to bone resorption (4). Based on this mechanism, denosumab, the 

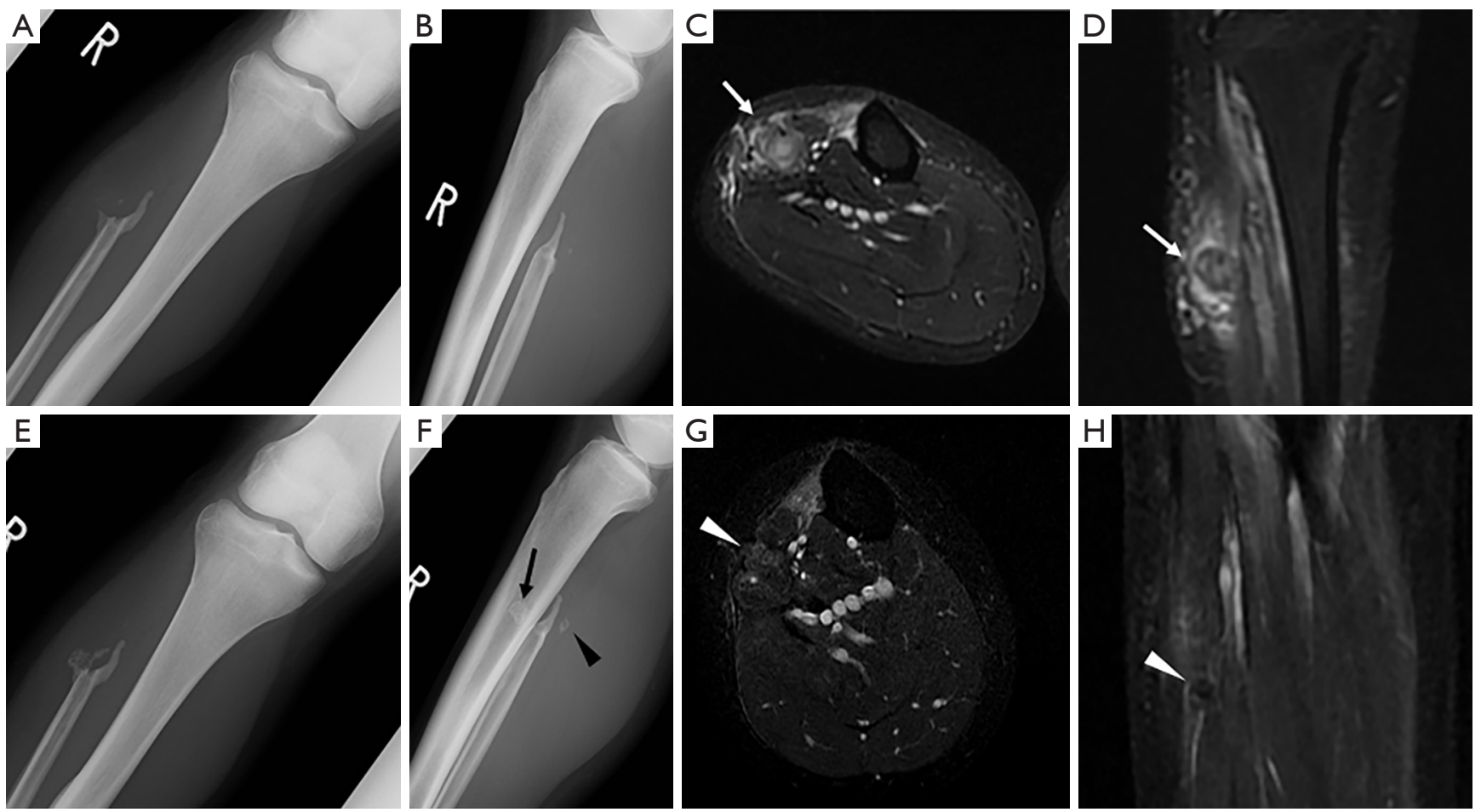

Figure 2 Radiological findings of before and after the denosumab treatment for recurrent GCTB. At 19 months after the initial operation, plain radiographs of the right lower leg show a tiny ossification in the soft tissue of the posterior to fibula stump (A,B). MRI demonstrating a soft tissue mass considered a recurrent lesion (arrow), displaying heterogeneously high intensity on STIR images (C, axial; D, coronal). After 6 months of preoperative denosumab treatment, the recurrent lesion is reduced in size and eggshell-like ossification appears (black arrow), and another ossification appeared in the surrounding soft tissue inferior to the fibula stump (black arrowhead) on plain radiographs (E,F). MRI showing the shrunken low-intensity mass on STIR (G, axial; H, coronal). GCTB, giant cell tumor of bone.

monoclonal antibody against RANKL, has been used to treat patients with GCTB (5).

Recently, a mutation of the histone family member $3 \mathrm{~A}$ gene $(\mathrm{H} 3 \mathrm{~F} 3 \mathrm{~A})$ was identified as the driver mutation of GCTB. Behjati et al. (6) reported that the $\mathrm{H} 3 \mathrm{~F} 3 \mathrm{~A}$ mutation was found in $92 \%$ of GCTB. This mutation was also observed in spindle cells and mononuclear cells appeared following denosumab treatment (7). Thus, H3F3A-mutated tumor cells survive after denosumab treatment and related to bone formation.

Our patient had a GCTB of the fibular head. Following the fibular head resection, this tumor visibly and invisibly recurred in the circumferential soft tissue, but it was visualized and easily resected following preoperative denosumab treatment. Preoperative denosumab treatment for GCTB has been reported to induce disappearance of osteoclast-like multinuclear giant cells microscopically, as well as morphological changes including eggshell-like ossification and shrinkage of tumor $(7,8)$. Akaike et al. (9) and Niu et al. (10) reported cases of soft-tissue recurrent GCTB treated surgically with the support of preoperative denosumab treatment, and they suggested that eggshelllike mineralization makes the surgical resection easier. Our present experience also indicates that preoperative denosumab treatment for a soft-tissue recurrence of GCTB is beneficial for a subsequent surgical resection by enabling the visualization of the recurrent lesion for patients in whom extraosseous recurrence is strongly suspected. The eggshell-like mineralization following preoperative denosumab treatment made the marginal resection easier, too. Although local recurrence of GCTB after three years from initial treatment is reported to be rare, late recurrence more than four years and malignant transformation more than ten years after treatment were reported (11). Therefore, a long-term, meticulous follow-up is essential. 

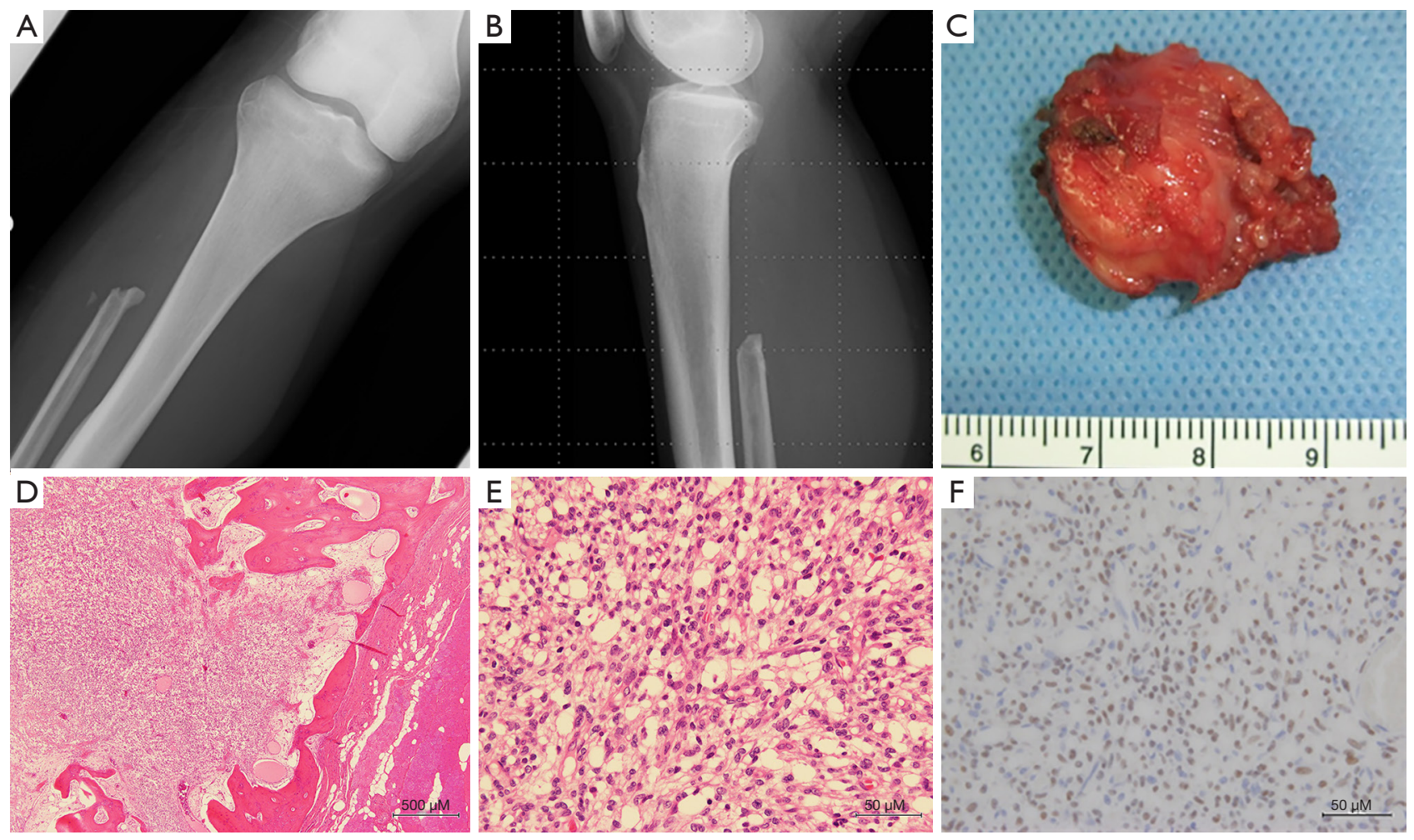

Figure 3 Plain anteroposterior (A) and lateral (B) radiographs taken after the second operation show no ossification lesion. The resected specimen as $28 \times 23 \mathrm{~mm}^{2}$ in size (C). Histopathological examination of the resected lesion showing peripheral bony shell surrounding the tumor tissue consisting of mononuclear neoplastic stromal cells and foamy cells (D, HE staining $\times 40$, low-power field), but osteoclast-like multinuclear giant cells are absent (E, HE staining, high-power field). Mononuclear neoplastic stromal cells showing immunopositivity for H3.3 G34W (F, ×400, high-power field).

\section{Acknowledgments}

Funding: None.

\section{Footnote}

Conflicts of Interest: All authors have completed the ICMJE uniform disclosure form (available at http://dx.doi. org/10.21037/qims-20-1157). The authors have no conflicts of interest to declare.

Ethical Statement: The authors are accountable for all aspects of the work in ensuring that questions related to the accuracy or integrity of any part of the work are appropriately investigated and resolved. All procedures performed in studies involving human participants were in accordance with the ethical standards of the institutional and/or national research committee(s) and with the Helsinki Declaration (as revised in 2013). Written informed consent was obtained from the patient for publication of this study and any accompanying images. A copy of the written consent is available for review by the Editor-in-Chief of this journal.

Open Access Statement: This is an Open Access article distributed in accordance with the Creative Commons Attribution-NonCommercial-NoDerivs 4.0 International License (CC BY-NC-ND 4.0), which permits the noncommercial replication and distribution of the article with the strict proviso that no changes or edits are made and the original work is properly cited (including links to both the formal publication through the relevant DOI and the license). See: https://creativecommons.org/licenses/by-nc-nd/4.0/.

\section{References}

1. Campanacci M, Baldini N, Boriani S, Sudanese A. Giant 
cell tumor of bone. J Bone Joint Surg Am 1987;69:106-14.

2. Balke M, Ahrens H, Streitbuerger A, Koehler G, Winkelmann W, Gosheger G, Hardes J. Treatment options for recurrent giant cell tumors of bone. J Cancer Res Clin Oncol 2009;135:149-58.

3. Klenke FM, Wenger DE, Inwards CY, Rose PS, Sim FH. Giant cell tumor of bone: Risk factors for recurrence. Clin Orthop Relat Res 2011;469:591-9.

4. Singh AS, Chawla NS, Chawla SP. Giant-cell tumor of bone: treatment options and role of denosumab. Biologics 2015;9:69-74.

5. Hakozaki M, Tajino T, Yamada H, Hasegawa O, Tasaki K, Watanabe K, Konno S. Radiological and pathological characteristics of giant cell tumor of bone treated with denosumab. Diagn Pathol 2014;9:111.

6. Behjati S, Tarpey PS, Presneau N, Scheipl S, Pillay N, Van Loo P, Wedge DC, Cooke SL, Gundem G, Davies H, Nik-Zainal S, Martin S, McLaren S, Goodie V, Robinson B, Butler A, Teague JW, Halai D, Khatri B, Myklebost O, Baumhoer D, Jundt G, Hamoudi R, Tirabosco R, Amary MF, Futreal PA, Stratton MR, Campbell PJ, Flanagan AM. Distinct $\mathrm{H} 3 \mathrm{~F} 3 \mathrm{~A}$ and $\mathrm{H} 3 \mathrm{~F} 3 \mathrm{~B}$ driver mutations define

Cite this article as: Suzuki T, Kaneuchi Y, Hakozaki M, Yamada H, Yamada S, Konno S. Visualization of hidden softtissue recurrence of giant cell tumor of bone enabled by preoperative denosumab treatment: a case description. Quant Imaging Med Surg 2021;11(8):3893-3897. doi: 10.21037/qims-201157 chondroblastoma and giant cell tumor of bone. Nat Genet 2013;45:1479-82.

7. Kato I, Furuya M, Matsuo K, Kawabata Y, Tanaka R, Ohashi K. Giant cell tumours of bone treated with denosumab: histological, immunohistochemical and H3F3A mutation analyses. Histopathology 2018;72:914-22 .

8. Agarwal A, Larsen BT, Buadu LD, Dunn J, Crawford R, Daniel J, Bishop MC. Denosumab chemotherapy for recurrent giant-cell tumor of bone: A case report of neoadjuvant use enabling complete surgical resection. Case Rep Oncol Med 2013;2013:496351.

9. Akaike K, Suehara Y, Takagi T, Kaneko K, Saito T. An eggshell-like mineralized recurrent lesion in the popliteal region after treatment of giant cell tumor of the bone with denosumab. Skeletal Radiol 2014;43:1767-72.

10. Niu X, Yang Y, Wong KC, Huang Z, Ding Y, Zhang W. Giant cell tumour of the bone treated with denosumab: How has the blood supply and oncological prognosis of the tumour changed? J Orthop Translat 2018;18:100-8.

11. Mohaidat ZM, Al-jamal HZ, Bany-Khalaf AM, Radaideh AM, Audat ZA. Giant cell tumor of bone: Unusual features of rare tumor. Rare Tumors 2019;11:2036361319878894. 